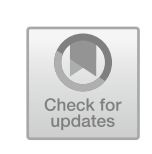

\title{
GE Appliances: An American Catalyst
}

In June 2016, Haier purchased GE Appliances for several billion dollars. Headquartered in Louisville, Kentucky, GEA had previously been a division of General Electric's global conglomerate. It was not a failing company when taken over, but it had been stagnant, showing no growth in market share or profits, a moribund management style, and little product innovation. Employee numbers had been cut from their peak of 23,000 in 1971 to 9,500 by 1995 . By 2015 , with profits now falling, and management having to negotiate cost-cutting measures such as reducing starting factory wages to $\$ 12$ /hour, GE had had enough. It tried, unsuccessfully, for over a year to find a buyer for its domestic appliances division until Haier bought the business in 2016 as part of its own ongoing internationalization strategy. Haier also acquired the right to keep the GE brand for 40 years and outright ownership of GEA's existing appliance brands that included Hotpoint, Profile, and Monogram.

By end of 2017, only eighteen months after the Haier take-over, GEA was already showing double-digit profit growth, its best performance in ten years. As I write this in mid-2020, the company is now the fastestgrowing domestic appliances business in America, and has achieved an overall growth of employee numbers, now upward of 14,000, market share, shareholder value, and profitability of over $6 \%$. Much of this was achieved during the long months of the Covid-19 crisis when other companies were experiencing huge losses. 
Following the pattern of all Haier partnered subsidiaries, GEA began to implement the RenDanHeyi management model in 2017. This was at the same time that Kevin Nolan was appointed as the company's new CEO. Nolan is an engineer who had worked for GE the whole of his career. Before becoming CEO of GEA, he had risen to the level of Technical Director for GE. He is a man who has loved machines and being involved with machines since early childhood. When I first met him, in Qingdao just after his promotion to CEO, he said to me, "You can't do this job properly unless you love machines. I love machines!" He told me that his way of unwinding after a long day of executive work is to go home to his garage and "fiddle with my machines." Later I learned that he spends long hours of his weekends in the engineering and design laboratory of First Build, the company's incubation hub, "playing" with the machines and experimenting with new things to invent. During the years of his career so far, he has obtained thirty-nine personal patents for his inventions. When we met for a second time in St. Louis and he arranged we visit First Build together, he spent the required amount of time for introductions and pleasant chat before escaping into the engineering and design lab to see what his young inventors were up to that day. Through the glass window of the door I saw him listening to them with excitement and rubbing his hand on their machines, as a father might fondly caress the heads of his children.

Nolan has always loved challenges, but he admits that at first he was not ready for the challenge of implementing RenDanHeyi at GEA. Like many of the American company leaders who are among the 10,000 visitors to Haier in Qingdao every year, he wasn't sure it could ever work in an American company. "It started off rough," he reflected later. "I had never seen a business operate like Haier, and it was very new territory. But then it got better." And there was an incentive to try. GE had been trying to offload its Appliances division for some time, causing many people to leave the company and low morale among those who stayed. "We felt unwanted," said Nolan, "and now we had been bought by someone who really wanted us. We all knew we were going to have to do something different."

During the first year after its acquisition by Haier, and still led by a CEO who had managed the company for GE, GEA remained a pretty much a standard, integrated company run from the top. At its core was an efficiency-focused, function-by-product matrix run by a vice president of Product Management. Everyone but him, the CFO, and a few other vice 
presidents reported directly to the CEO, and all decisions were centralized. As when owned by GE, most company products were moved to market through big retail chains like Home Depot, Sears, and Best Buy, and it was they who dealt with any customer service needs. An information firewall between GEA and these retail distributors denied GEA nearly all direct knowledge about the customers who were using the company's products. I met that original CEO at a lunch with Zhang Ruimin in Qingdao and commented to Zhang afterward, "He will never 'get it'." Zhang nodded knowingly, and within six months, Kevin Nolan had replaced him.

Nolan had spent those six months in Qingdao, learning everything he could about how RenDanHeyi worked at Haier, and for the first six months of his tenure as CEO he had the benefit of regular help and coaching from Haier's Foreign Acquisitions Manager by phone from Qingdao. "But ever since then," Nolan now says, "Haier has just left us to get on with it. They have great respect for national and cultural differences and feel strongly that management is best left to local leaders who know their regions and their people. Aside from a once-a-month, casual catch-up call with Qingdo, we are left to adapt RenDanHeyi to our own needs and purposes. I have never known such light-touch management from central office, and I think our partnership is a great example of what can be achieved through the cooperation of American and Chinese companies."

Once Kevin Nolan was in charge of GEA, he began the process of ridding the company of much of its centralized bureaucracy and breaking it down into Haier-style, independent, and self-organizing microenterprises serviced by central platforms. There are now fifteen of these, plus the First Build innovation hub inherited from the later GE days, making up the company so far, and direct contact with users through company IT channels has become a priority, as has taking control of GEA's own distribution and customer service operations. The company now maintains an extensive factory service system that is nearly unique in the appliances industry, and its answer centers deal with over 10 million customer calls each year. Where the original company had operated under a single brand, GEA has now become a "House of Brands," with each brand having different features that appeal to different user segments-a nascent version of Haier's own, more user-customized product "scenarios." Employee bonus compensation has also become much more democratic. During that first year after acquisition by Haier, only 170 top executives were 
receiving bonus payments; today nearly 3000 employees receive them. Not yet Haier's own, revolutionary pay-at-point-of-user scheme whereby microenterprise employees receive the bulk of their pay directly from their customers, but instead each bonus payment reflects a share of overall company profits, a share of microenterprise profits, plus individual KPI indicators.

GEA is now run by 3-person Executive Council that includes Kevin Nolan but, following key principle of RenDanHeyi, the power pyramid is inverted. As at Haier itself, the company's operating principle has become, "The Owner [of the product] is the Boss," The user is now at the top of the power pyramid, and the Executive Council at the bottom. This policy was laid out very clearly in "Creating the 5-Year Plan," a GEA internal communication circulated in August 2017:

Transforming GEA to accelerate our growth starts with shifting the focus from inside-out to outside-in. We've traditionally had the approach of "management is the boss," where we make decisions based on management views, assessments, goals, etc. ..... Everything we do now, how we're structured, what we make, and so on, must be geared to delivering on the owners' needs/desires. The more focused and connected we are to the owners, the more value we will deliver and the more successful we will be. ${ }^{l}$

noindentBetween the owners and the Executive Council, and in direct contact with the owners, sit the microenterprises in the power pyramid. They make all decisions about product development and service and essentially determine all company strategies. GEA no longer has a Strategy Department, and Nolan says he leaves day-to-day running of the company to the microenterprises. "Usually," he says, "I don't even know what's happening until someone tells me." But the GEA microenterprises, while independent and self-organizing, are not complete companies, incorporating all functions in themselves as at Haier. Instead, things like sales, marketing, and distribution are left to shared service platforms.

GEA's First Build incubation hub is still the company's showpiece for breakthrough innovation, and is required to invent twelve new products each year. Its sole purpose is to discover unmet needs. Located on the

${ }^{1}$ Dennis Campbell et al., "GE Appliances: Implementing Haier's Made-in-China Management System,” p. 11. 
campus of the University of Kentucky, the massive and well-equipped First Build design and engineering lab is open to the community and often sees local high school students and students from the university working alongside GEA's own designers on the well-equipped facilities. It maintains a boundaryless, open-innovation policy, remains open during evenings and weekends, and buzzes with an air of constant excitement and invention. On the day of my own visit, two young men were demonstrating their just-completed, domestic-sized food smoking appliance by offering us all samples of still-warm, succulent smoked salmon. Inspired by this, I suggested, "You know, you really should follow this up with a domestic wood-burning pizza oven," but as the words left my mouth, another young designer took me by the elbow, led me across the room and, pointing to a nearly finished oven-style cabinet, said, "Take a look at this!" As someone who had built my own atom-smashing devices in my bedroom during my teenage years, I was loathed to leave First Build after my visit.

\section{GEA AND THE COVID-I9 CRISIS}

In an interview he gave in late September 2020, Kevin Nolan commented, "It was when the Covid-19 crisis hit us that RenDanHeyi really proved what it could do." Here's how GEA thrived and grew when most American manufacturing and retail companies were struggling or failing.

"When the Covid challenge became clear," says Nolan, "we realized that we were facing the most unpredictable and chaotic event of our lives. We stopped all work for three days and everyone just thought things through. We asked, 'How can we best respond to this? How do we operate now.'” As a result, GEA defined guiding principles instead of detailed plans: "Protect our people. Protect our business. And focus on supporting and meeting the needs of our customers and community." They articulated a crisis slogan to reassure and inspire both their own people and their customers: "When Covid keeps us apart, RenDanHeyi brings us together." And, perhaps most importantly, they adopted a positive attitude: to see the Covid crisis as an opportunity to grow the business.

"The crisis really brought out the entrepreneurial spirit," says Nolan. "Everyone pivoted immediately to meet users' new needs and to discover new business opportunities." Before long they noticed that during the lockdown restrictions, people were using their domestic appliances more. 
Cooking more, doing laundry more frequently, and they saw they needed to step up production and really utilize the agility of their supply chains. Each microenterprise looked at its own users and its own supply chains. They helped users with their extra financial needs and made it a priority to get appliances and services to front-line workers by reaching out to them with a national campaign. They helped their independent outlets keep up with extra demand by providing online, brand training videos. Employees put in 157,000 volunteer man hours during the crisis, and even senior management, including lawyers, built machines. Instead of cutting back on production, GEA introduced new product lines during the crisis and launched direct consumer channels. No one was laid off or made redundant; instead, hundreds of new employees were hired. And the work they had done to make their factories safe during all this got GEA recognized as having the safest factories in America.

"Covid really proved the speed and the agility of RenDanHeyi," says Nolan. "The crisis moved us forward. It made us a better company. We will now be a lot more future proof." Summing up GEA's Covid experience, he adds, "Traditional organizations act as if the future can be predicted. They are living in a fantasy world. We have got to build our companies around the fact of constant, future crises like this. Covid won't be the last. We are no longer living in the world of plans and efficiencies."

Efficiency and bottom line goals are now replaced at GEA by an aspirational leading target: "To be the number one company in the American appliance industry - in terms of being seen as the most talked about and most exciting company." During the heady days of my own visit to the company, I felt they had already come a long way toward being that "most exciting company in America." 
Open Access This chapter is licensed under the terms of the Creative Commons Attribution-NonCommercial-NoDerivatives 4.0 International License (http:// creativecommons.org/licenses/by-nc-nd/4.0/), which permits any noncommercial use, sharing, distribution and reproduction in any medium or format, as long as you give appropriate credit to the original author(s) and the source, provide a link to the Creative Commons license and indicate if you modified the licensed material. You do not have permission under this license to share adapted material derived from this chapter or parts of it.

The images or other third party material in this chapter are included in the chapter's Creative Commons license, unless indicated otherwise in a credit line to the material. If material is not included in the chapter's Creative Commons license and your intended use is not permitted by statutory regulation or exceeds the permitted use, you will need to obtain permission directly from the copyright holder.

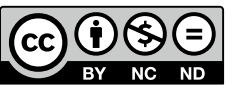

